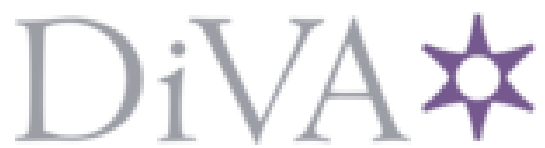

http://www.diva-portal.org

This is the published version of a paper presented at 28th IEEE International Conference on Micro Electro Mechanical Systems (MEMS), JAN 18-22, 2015, Estoril, PORTUGAL.

Citation for the original published paper:

Forsberg, F., Roxhed, N., Colinge, C., Stemme, G., Niklaus, F. (2015)

Integration of distributed Ge islands onto Si wafers by adhesive wafer bonding and lowtemperature Ge exfoliation

In: 2015 28th IEEE International Conference on Micro Electro Mechanical Systems (MEMS 2015) (pp. 280-283). IEEE

Proceedings IEEE Micro Electro Mechanical Systems

https://doi.org/10.1109/MEMSYS.2015.7050943

N.B. When citing this work, cite the original published paper.

Permanent link to this version:

http://urn.kb.se/resolve?urn=urn:nbn:se:kth:diva-184061 


\title{
INTEGRATION OF DISTRIBUTED GE ISLANDS ONTO SI WAFERS BY ADHESIVE WAFER BONDING AND LOW-TEMPERATURE GE EXFOLIATION
}

\author{
F. Forsberg ${ }^{1}$, N. Roxhed ${ }^{1}$, C. Colinge ${ }^{2}$, G. Stemme ${ }^{1}$ and F. Niklaus ${ }^{1}$ \\ ${ }^{1}$ Micro and Nanosystems, KTH Royal Institute of Technology, Stockholm, Sweden \\ ${ }^{2}$ California State University, Sacramento, USA
}

\begin{abstract}
We present a novel and highly efficient wafer-level batch transfer process for populating silicon (Si) wafers with distributed islands of thin single-crystalline germanium $(\mathrm{Ge})$ layers. This is achieved by transferring Ge from a Si wafer containing thick Ge dies to a Si target wafer by adhesive wafer-bonding and subsequent lowtemperature Ge exfoliation.
\end{abstract}

\section{INTRODUCTION}

The combination of electronic, MEMS and photonic functions on a common $\mathrm{Si}$ substrate enable highperformance heterogeneous microsystems such as infrared detector arrays, optical gyroscopes or components for optical communication systems [1-7]. However due to the lattice mismatch between $\mathrm{Si}$ and typical photonic materials such as Ge, gallium-arsenide (GaAs) or indium phosphide (InP), it is in most cases not possible to directly deposit or grow these type of high-quality photonic materials on top of a Si substrate. An attractive approach to overcome this problem is to transfer a layer of the highquality photonic material from its original substrate to the Si substrate. This has been implemented mainly by using chip-level processes based on adhesive bonding [8,9] or direct bonding [10]. In these approaches the photonic material donor substrate typically is sacrificially etched after the bonding step to leave a thin layer of the photonic material on top of the Si substrate. Thereafter the photonic devices on the Si substrate can be defined and formed from the photonic material. However, these processes are very resource demanding since the comparably expensive photonic material substrates are sacrificially removed by grinding and/or etching. Furthermore, due to the difference in coefficient of thermal expansion (CTE) between $\mathrm{Si}$ and e.g. Ge or GaAs, it is extremely challenging to utilize large-scale and high-yield wafer-towafer bonding at elevated temperatures. An innovative approach to address this problem is to populate the $\mathrm{Si}$ wafer with pre-dices dies of the photonic material using pick-and-place positioning of the dies on the wafer along with a subsequent adhesive wafer bonding step. All dies on the Si wafer can then be thinned and processes in parallel fashion using standard wafer-scale processes $[3,6]$. Another related process that has been proposed is based on batch-transfer of radially expanded die arrays to achieve efficient layer transfer [11]. However, both these approaches rely on sacrificial removal of the excess photonic donor substrate. In this work we present a waferlevel batch transfer process that is based on transferring Ge from a Si wafer that is containing Ge dies to a Si target wafer by adhesive wafer-bonding and subsequent lowtemperature Ge exfoliation from the Ge dies. The bulk of the $\mathrm{Ge}$ dies is remaining on the $\mathrm{Si}$ wafer and can in principle be reused to transfer subsequent layers from the remaining bulk Ge dies. Thus, the proposed approach circumvents problems caused by the CTE mismatch between $\mathrm{Si}$ and photonic material wafers and avoids the sacrificial removal of the comparably expensive photonic base substrate.

\section{CONCEPT OF THE INTEGRATION PROCESS AND EXPERIMENTS}

The conceptual idea for the transfer of thin Ge layers from $\mathrm{Ge}$ dies onto a Si wafer consists of starting with a Si wafer containing distributed island of Ge dies. This is used as the Ge donor-wafer which is then adhesively bonded to a receiving $\mathrm{Si}$ substrate. Adhesive bonding is attractive for heterogeneous integration processes due to its insensitivity to topographies or particles at the surfaces to be bonded and the resulting high-yield bond interfaces [1]. Since both the target wafer and the donor wafer containing the $\mathrm{Ge}$ dies are made of $\mathrm{Si}$, there is no significant CTE mismatch between the two wafers, which avoids problems related to a CTE mismatch during bonding. The hydrogen-implanted $\mathrm{Ge}$ dies are exfoliated at a comparably low temperature of $300^{\circ} \mathrm{C}$ [5], which leaves transferred $1 \mu \mathrm{m}$ thick Ge layers on the Si target wafer. Figure 1 shows the detailed process scheme that was implemented in this work. In this process, hydrogen is implanted in a Ge wafer surface to a depth of about $1 \mu \mathrm{m}$ as indicated in Figure 1a. Thereafter a $1 \mu \mathrm{m}$ thick layer of silicon nitride is deposited on the surface of the $\mathrm{Ge}$ wafer using plasma-enhanced chemical vapor deposition as depicted in Figure 1b. Next, the wafer is attached to an expandable UV-release tape and diced into $\mathrm{mm}$-sized dies as shown in Figure 1c. The array with dies is then expanded as depicted in Figure 1d using a matrix expander [4]. A Si wafer is spin-coated with AP3000 adhesion promoter (Dow Chemical Company) at $3000 \mathrm{rpm}$ and spun dry. This is followed by spin-coating a layer of BCB (Cyclotene 3022-46, Dow Chemical Company) that is mesitylene-diluted $1: 1$ by weight at $5000 \mathrm{rpm}$ onto the $\mathrm{Si}$ wafer as shown in Figure 1e. The dilution of the $\mathrm{BCB}$ is done to obtain a very thin $\mathrm{BCB}$ coating with a thickness of about $550 \mathrm{~nm}$. The spin-coated $\mathrm{BCB}$ on the Si wafer is soft-baked at $150^{\circ} \mathrm{C}$ for 3 min on a hotplate and subsequently slightly crosslink for $5 \mathrm{~min}$ at $180^{\circ} \mathrm{C}$ in an oven. Thereafter, the tape with the expanded Ge die array is pressed onto the BCB-covered wafer and baked for $10 \mathrm{~min}$ at $80^{\circ} \mathrm{C}$ as shown in Figure 1f. The dicing tape is removed by exposing the tape for $10 \mathrm{~min}$ to UV-radiation as shown in Figure 1g. A second BCBcoated $\mathrm{Si}$ wafer is prepared by spin-coating the wafer with the adhesion promoter AP3000 at $3000 \mathrm{rpm}$ until the 
wafer is dry and then spin-coating an undiluted layer of $\mathrm{BCB}$ (Cyclotene 3022-46) at $5000 \mathrm{rpm}$ on the Si wafer. This results in a $2.4 \mu \mathrm{m}$ thick layer of BCB-layer, as depicted in Figure 1h. The BCB-coated Si wafer is then bonded to the $\mathrm{Si}$ wafer containing the $\mathrm{Ge}$ dies as illustrated in Figure 1i. The wafer bonding is performed in a Suss Microtec SB8 wafer bonder. The combined wafer bonding and $\mathrm{Ge}$ exfoliation process consists of $24 \mathrm{~h}$ baking at $130^{\circ} \mathrm{C}$, followed by a temperature ramp of $1^{\circ} \mathrm{C}$ per minute to $300^{\circ} \mathrm{C}$. The bonding temperature is kept stable for $10 \mathrm{~min}$ followed by cooling the wafer stack to room temperature. The temperature cycling steps crack the thin hydrogen-implanted layer from the surface of the Ge dies at the depth of the hydrogen-implantation [12]. This leaves thin, exfoliated Ge layers bonded with BCB on the target wafer. The bulk Ge dies remain bonded to the Si wafer as illustrated in Figure $1 \mathrm{j}$.

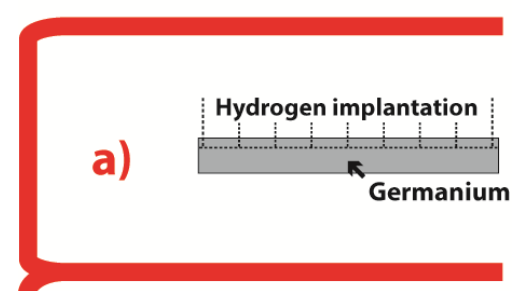

d)

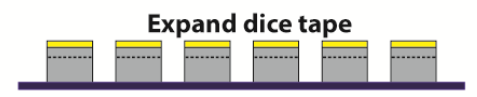

Flip up side down
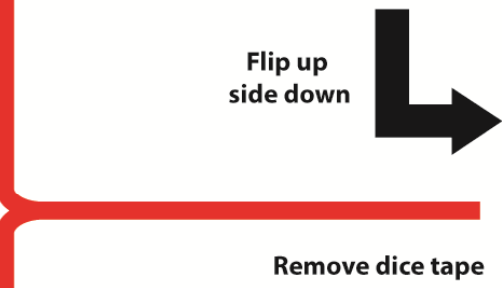

g)

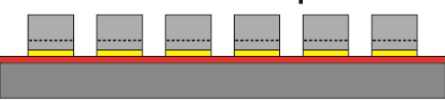

b)

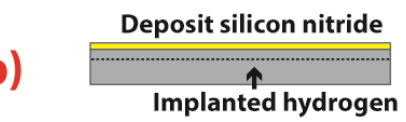

\section{Expand dies and transfer to Si wafer}

\section{Implant hydrogen and} dice into dies

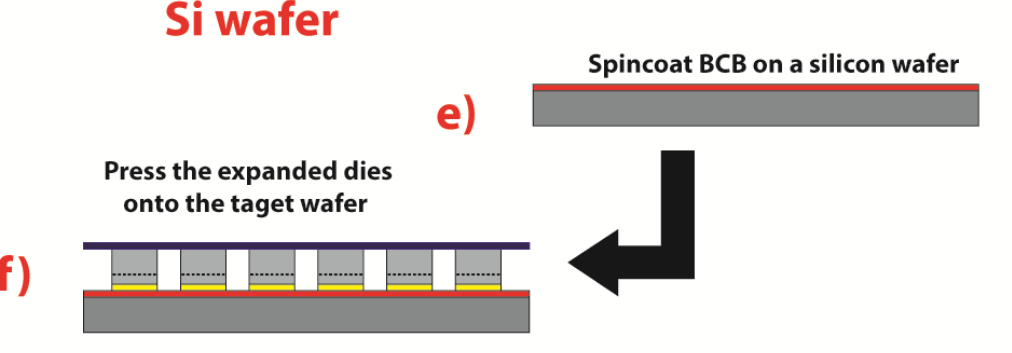

\section{Wafer bonding}

c)

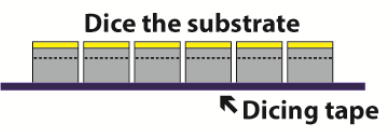

Adhesively bond the dies to the Si substrate

\section{h)}

Spincoat BCB on a silicon wafer

)

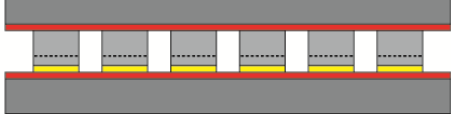

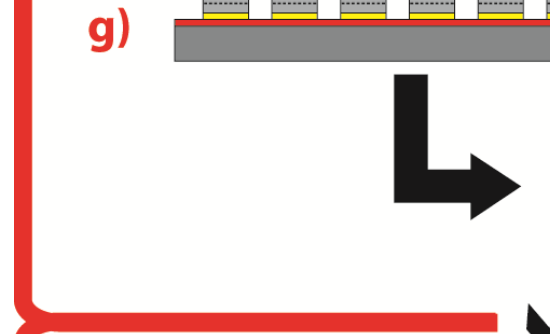

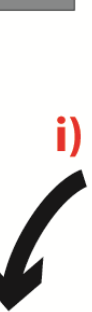

Ge exfoliation

j)
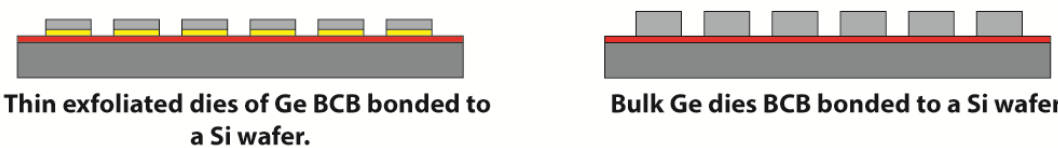

Bulk Ge dies BCB bonded to a Si wafer.

\section{Detailed fabrication scheme}

Figure 1: (a) Hydrogen is implanted into a Ge wafer. (b) Deposit $1 \mu \mathrm{m}$ PECVD silicon nitride onto the Ge wafer. (c) Dice the Ge wafer. (d) Expand the dicing tape to separate the dies. (e) Spin coat BCB onto a Si wafer. (f) Press the expanded die array onto the Si wafer. (g) Remove the dicing tape after the transfer. (h) Spin-coat BCB on a second Si wafer. (i) Press the Si wafer onto the Si wafer containing the Ge dies. Bond the two wafers. (j) Exfoliation of the thin hydrogen-implanted Ge layer by temperature ramping to $300^{\circ} \mathrm{C}$. This process causes the cracking of a thin layer of Ge from the surface of the Ge dies. Thus, $800 \mathrm{~nm}$ thick exfoliated Ge layers are left on the Si target wafer. The bulk Ge dies remain bonded on the Si handle wafer.

\section{RESULTS}

Figure 2 depicts experimental results from studying the fabrication process as described in Figure 1. Figure 2a shows a $15 \mathrm{~mm}$ square $\mathrm{Ge}$ die that is attached to an expandable dicing tape. Figure $2 b$ shows the same Ge die after dicing and tape expansion to separate the Ge dies before their transfer to a Si wafer using adhesive bonding.
Figure 2c shows four arrays of $\mathrm{Ge}$ dies bonded to a $\mathrm{Si}$ wafer as depicted in Figure 1g. The dies are squares and have sizes of $2 \mathrm{~mm}, 2.5 \mathrm{~mm}, 3 \mathrm{~mm}$ and $5 \mathrm{~mm}$ respectively. Figures 3 and 4 illustrate the results following the wafer bonding and Ge exfoliation steps as depicted in Figure 1i and 1j. Figure $3 \mathrm{a}$ and $3 \mathrm{~b}$ are images of $\mathrm{Si}$ wafers with bonded and exfoliated $\mathrm{Ge}$ dies. 
Figure 3a shows a Si handle wafer with adhesively bonded bulk Ge dies after the Ge exfoliation step. Figure $3 \mathrm{~b}$ shows the respective $\mathrm{Si}$ target wafer containing the transferred $1 \mu \mathrm{m}$ thick Ge layer islands. Figure 4a shows the results from an EDX material analysis to confirm that $\mathrm{Ge}$ has been transferred. Figure $4 \mathrm{~b}$ shows one bulk Ge die on the donor wafer after exfoliation. Figure $4 \mathrm{c}$ shows a transferred and exfoliated Ge layer island on the target $\mathrm{Si}$ wafer.

a)

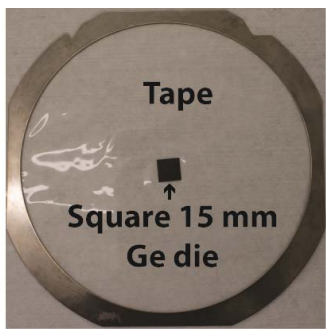

b)

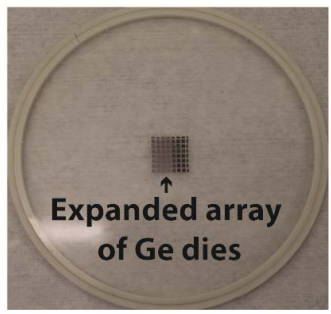

c)

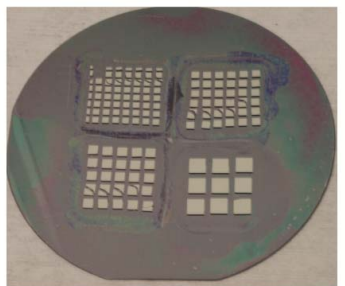

Figure 2: (a) Square $15 \mathrm{~mm}$ Ge die attached to an expandable UV-release dicing tape. Results following the step shown in Figure 1c. (b) Expanded die array. Results following the step shown in Figure 1d. (c) Four arrays of dies transferred and $B C B$-bonded to a $100 \mathrm{~mm}$ diameter Si wafer. Results following step shown in Figure $1 \mathrm{~g}$.

a)

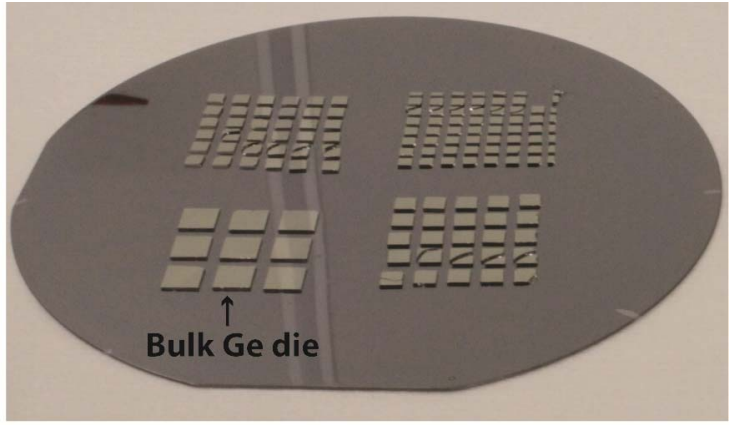

b)

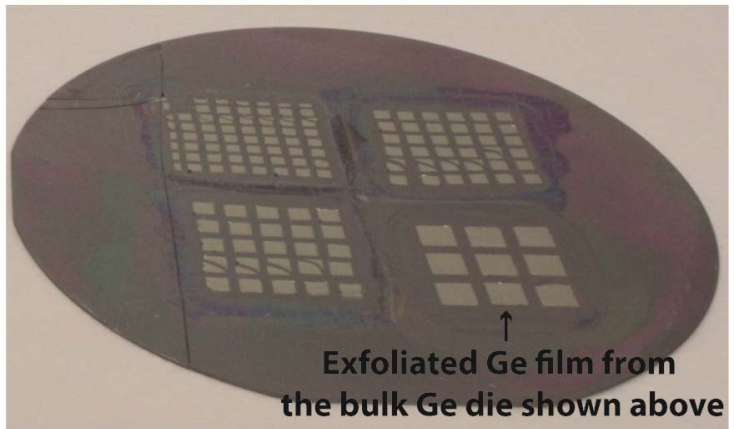

Figure 3: (a) Bulk Ge dies BCB bonded to a $100 \mathrm{~mm}$ diameter Si wafer. Results following step shown in Figure 1j. (b) Thin exfoliated Ge layer islands that are $B C B$ bonded to a $100 \mathrm{~mm}$ diameter Si wafer. Results following step shown in Figure $1 j$. a)

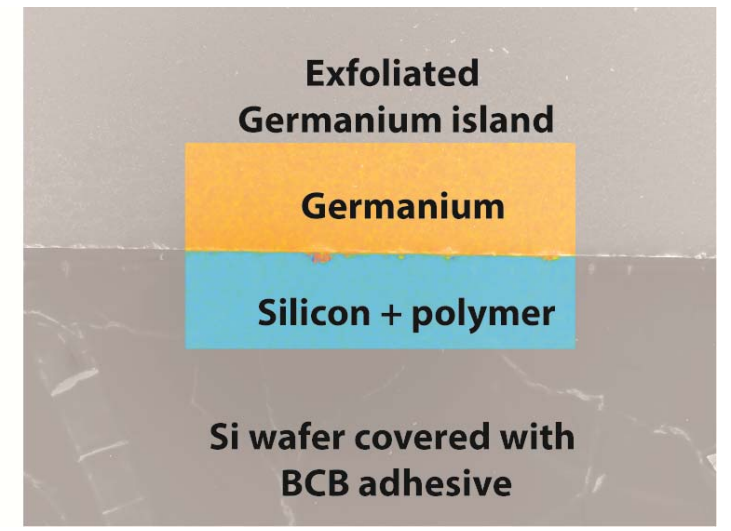

b)

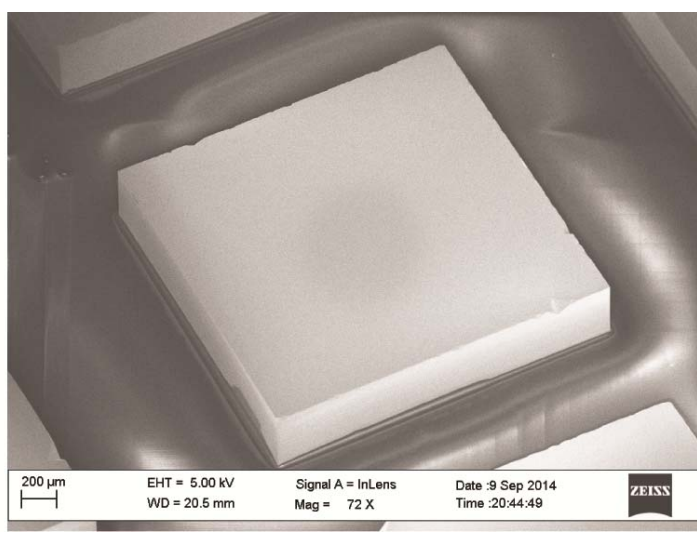

c)

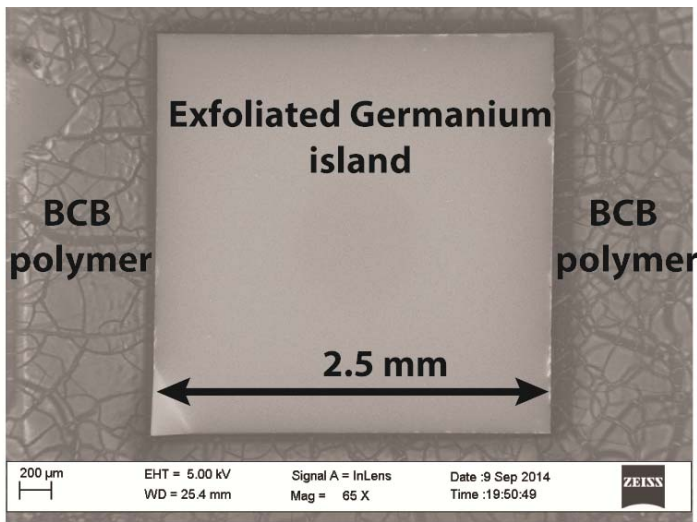

Figure 4: (a) EDX scan confirming that Ge was transferred. The color coding corresponds to concentration of Ge and Si. (b) SEM image of a bulk Ge die on the $\mathrm{Si}$ donor wafer after exfoliation. (c) Transferred and exfoliated Ge thin layer island that is bonded to the Si target wafer.

The results from the experiments depicted in Figures 2, 3 and 4 conclusively demonstrate that it is possible to use adhesive bonding and subsequent exfoliation of thin Ge layers to transfer $\mathrm{Ge}$ from a donor wafer and populate a $\mathrm{Si}$ target wafer with thin-film Ge islands in a controlled way. This approach could be a step towards cost-competitive and resource efficient heterogeneous integration of active photonic materials in Si-based platforms. Potential applications could be advanced heterogeneous $\mathrm{Si}$ photonics for optical communication systems and highperformance infrared bolometer arrays. 


\section{CONCLUSIONS}

In summary, we have demonstrated the viability of a new process scheme for resource efficient and wafer-level transfer of high-quality photonic materials, in this case $\mathrm{Ge}$, on top of a silicon wafer. The proposed heterogeneous integration process is based on adhesive wafer bonding with $\mathrm{BCB}$ as the intermediate bonding layer and subsequent exfoliation of a thin layer from the photonic material donor substrate. The process can be implemented on wafer-level and is potentially more resource efficient than conventional schemes using chip-to-wafer bonding together with sacrificial substrate removal.

\section{ACKNOWLEDGEMENTS}

This work was supported by the European Commission through the Grant No.277879 and Grant No.267528.

\section{REFERENCES}

[1] F. Forsberg, et al., "CMOS-Integrated Si/SiGe Quantum-Well Infrared Microbolometer Focal Plane Arrays Manufactured With Very Large-Scale Heterogeneous 3D Integration", IEEE Journal of Selected Topics in Quantum Electronics, Vol.21, 2014, DOI: 10.1109/JSTQE.2014.2358198.

[2] C. Sorrentino, J.R. Toland, "Ultra-Sensitive Chip Scale Sagnac Gyroscope Based on Periodically Modulated Coupling of a Coupled Resonator Optical Waveguide", Optics Express, Vol.20, No.1, pp.354$363,2012$.

[3] G. Roelkens, et al., "III-V/Si Photonics by Die-toWafer Bonding", Materials Today, Vol.10, No.7, pp.36-43, 2007.

[4] M. Smit, J. Brouckaert, D. Van Thourhout, R. Baets, R. Nötzel, G. Roelkens, "Adhesive Bonding of InP/InGaAsP Dies to Processed Silicon-On-Insulator Wafers using DVS-bis-Benzocyclobutene", Journal of The Electrochemical Society, Vol.153, pp.1015$1019,2006$.

[5] A. Gassenq, F. Gencarelli, J. Van Campenhout, Y. Shimura, R. Loo, G. Narcy, B. Vincent, G. Roelkens, "GeSn/Ge Heterostructure Short-Wave Infrared Photodetectors on Silicon", Optics Express, Vol.20, No.25, pp.27297-27303, 2012.

[6] M. Lapisa, G. Stemme, F. Niklaus, "Wafer-Level Heterogeneous Integration for MOEMS, MEMS and NEMS", IEEE Journal of Selected Topics in Quantum Electronics, Vol.17, No.3, pp.629-644, 2011.

[7] J. Brouckaert, G. Roelkens, D. Van Thourhout, R. Baets, "Thin-film III-V Photodetectors Integrated on Silicon-on-Insulator Photonic ICs", Journal of Lightwave Technology, Vol.25, No.4, pp.1053-1060, 2007.

[8] F. Niklaus, G. Stemme, J.-Q. Lu, R.J Gutmann, "Adhesive Wafer Bonding", Journal of Applied Physics, Vol.99, No.1, pp.031101.1-031101.28, 2006.

[9] F. Niklaus, P. Enoksson, E. Kälvesten, G. Stemme, "Low Temperature Full Wafer Adhesive Bonding", Journal of Micromechanics and Microengineering, Vol.11, No.2, pp.100-107, 2001.
[10]D. Liang, J.E. Bowers, D.C. Oakley, A. Napoleone, D.C. Chapman, C.-L. Chen, P.W. Juodawlkis, O. Raday, "High-quality $150 \mathrm{~mm}$ InP-to-silicon epitaxial transfer for silicon photonic integrated circuits", Electrochemical and Solid-State Letters, Vol.12, No.4, pp.H101-H104, 2009.

[11]F. Forsberg, N. Roxhed, T. Haraldsson, Y. Liu, G. Stemme and F. Niklaus, "Batch Transfer of Radially Expanded Die Arrays for Heterogeneous Integration Using Different Wafer Sizes", IEEE Journal of Microelectromechanical Systems, Vol. 21, No. 5, pp. 1077-1083, Oct. 2012.

[12] I.P. Ferain, K.Y. Byun, C.A. Colinge, S. Brightup, M.S. Goorsky, "Low Temperature Exfoliation Process in Hydrogen-Implanted Germanium Layers", Journal of Applied Physics, Vol.107, No.5, pp.054315, 2010.

\section{CONTACT}

* F. Forsberg; tel: +46-73 3944176; ffors@kth.se 